\title{
CAUSAS Y CONSECUENCIAS DEL CRECIMIENTO URBANÍSTICO EN EL LITORAL VALENCIANO A TRAVÉS DE LA EVOLUCIÓN DE LOS USOS DEL SUELO. EL CASO DE OLIVA ${ }^{1}$
}

\author{
Sergio Morell Monzó \\ Universitat de València \\ https://orcid.org/0000-0001-8883-2618 \\ Joan Carles Membrado-Tena \\ Universitat de València \\ https://orcid.org/0000-0001-6961-1449
}

\section{RESUMEN}

Mediante la fotointerpretación de imágenes aéreas con la utilización de técnicas SIG y a través de un intenso trabajo bibliográfico y de campo, se realiza un análisis diacrónico (1956, 1991 y 2015) de la evolución de los usos del suelo en Oliva (València, España). A partir de este análisis multimetodológico se estudia la evolución de la situación urbanística y de las dinámicas territoriales en un municipio paradigmático para explicar la evolución urbanística del litoral valenciano en las últimas décadas.

Palabras clave: SIG, fotointerpretación; usos del suelo; dinámica territorial; crecimiento urbano.

\section{Causes and consequences of the urban growth in the Valencian coast through land use} evolution. The case of Oliva

\section{ABSTRACT}

In this paper we have carried out a diachronic analysis about land uses evolution in Oliva through a mixed method of research, based on photo-interpretation of aerial images (years

Fecha de recepción: 17 de abril de 2018

Fecha de aceptación: 11 de diciembre de 2018

Departamento de Geografía. Universitat de València. Avda. Blasco Ibañez, 28. 46010 VALÈNCIA (España). E-mail: sergio.morell.monzo@gmail.com,joan.membrado@uv.es

1 Este artículo deriva del Trabajo de Fin de Máster defendido por Sergio Morell Monzó, con el título "De emporio de la naranja al caos territorial. Evolución de los usos del suelo de Oliva (València)”, dentro del Máster Universitario en Técnicas para la Gestión del Medio Ambiente y del Territorio del Departament de Geografia de la Universitat de València. Este trabajo fue dirigido por el profesor Joan Carles Membrado-Tena. 
1956, 1991, 2015) using GIS techniques, on the one hand, and by means of a comprehensive bibliographic and field work, on the other hand. From this multimethod analysis, urban development and territorial dynamics are studied in a coastal paradigmatic municipality to explain the urbanistic development of the Valencian Mediterranean coast in the last decades.

Keywords: GIS; photo-interpretation; land uses; territorial dynamics; urban growth.

\section{INTRODUCCIÓN}

A partir de los fotogramas aéreos de tres momentos (1956, 1991 y 2015) y la documentación científica recopilada, se realiza un análisis de la evolución de los usos del suelo del municipio de Oliva. Para ello se emplean diferentes técnicas SIG que permiten fotointerpretar, clasificar y cuantificar cada tipo de uso del suelo. La nomenclatura de cada tipo de cobertura se basa en la clasificación de CORINE Land Cover, aunque ha sufrido algunas modificaciones ad hoc para adaptarla a las características de la zona y a una escala municipal. Desde este punto de vista se realizará un análisis del crecimiento urbanístico del municipio y de sus dinámicas territoriales, así como sus causas, sus características y sus efectos.

\subsection{Hipótesis y objetivos}

Desde los años sesenta hasta la actualidad, las zonas litorales han experimentado un acelerado crecimiento de las superficies urbanas a través de sucesivos booms inmobiliarios. En Oliva, como en gran parte de los municipios litorales españoles con un potencial turístico elevado, los agentes económicos, las administraciones locales y estatales, y los particulares han obtenido un gran beneficio económico siguiendo una intensa política de urbanización y atracción turística. Estos intereses han provocado fuertes cambios sobre los usos del suelo y por tanto, sobre el paisaje del municipio y han impedido actuar con cautela considerando otros criterios (sociales, urbanísticos y ambientales) frente a procesos tan difícilmente reversibles como la ocupación urbana.

La elección de este municipio se ha realizado con la intención de explicar una realidad mayor a la que acontece a escala municipal; la del litoral mediterráneo español y más concretamente la del litoral valenciano. En este sentido, Oliva es uno de los municipios con mayor crecimiento urbanístico del mediterráneo en las últimas décadas y además, en la situación inicial de la que parte este estudio, destaca por su situación primigenia en lo que al desarrollo urbano se refiere. Además, Oliva es y ha sido un magnífico ejemplo de las políticas inmobiliarias y de atracción turística basadas en el producto sol y playa llevadas a cabo en la costa mediterránea española desde los años setenta. Por este motivo se presenta como un objeto de estudio especialmente interesante.

El objetivo de este trabajo es, por tanto, la cuantificación de los cambios en los usos del suelo de Oliva durante los periodos citados, con el fin de caracterizar y analizar los procesos y efectos que han tenido lugar en su término municipal a causa de la acción antrópica. 


\subsection{El caso de estudio}

Oliva forma parte de la comarca de La Safor (València), con capital en Gandia. Es el municipio costero más meridional de la comarca y se sitúa en el límite entre la provincia de València y la de Alacant. En el año 1956 la población de Oliva apenas superaba los 14.000 habitantes. Actualmente, según el INE, la población es de 25.488 habitantes. Con una superficie de $59,8 \mathrm{Km}^{2}$, es el segundo municipio más grande de su comarca y cuenta con una densidad de población de $426 \mathrm{hab} . / \mathrm{Km}^{2}$.

Desde el punto de vista económico, Oliva podría definirse como el extremo sur del área funcional de La Safor (Muñoz et al., 2010). No obstante, su posición periférica alejada del centro de área funcional y el papel que desempeña, sobre todo ligado al turismo, entre dos potencias económicas como Gandia y Dénia, lo sitúan como el nexo de unión entre las áreas funcionales de Gandia y la de la Marina Alta.

Desde el punto de vista fisiográfico el término municipal de Oliva se dispone, en su mayor parte, sobre una llanura litoral de origen tectónico complejo formada principalmente por materiales aluviales cuaternarios (Ajuntament d'Oliva, 2006). Al sur de la llanura encontramos el espacio palustre correspondiente al Parque Natural de la Marjal Pego-Oliva. Se trata de un humedal litoral (de formación tipo restinga-albufera) no colmatado debido a los importantes aportes de agua de los acuíferos de las montañas inmediatas (Viñals, 1996), que a su vez son los causantes de los manantiales y surgencias de agua que se encuentran a lo largo de la llanura. Esta amplia llanura litoral destaca por su gran simplicidad topográfica (con pendientes que no superan el 3\%), su gran aptitud agrícola y su alta disponibilidad de agua. Por este motivo los habitantes de Oliva han aprovechado tradicionalmente estas tierras para el cultivo citrícola, convirtiendo al municipio en uno de los emporios de la naranja del País Valenciano. Al oeste del término municipal se alzan la Serra Gallinera y Serra Mustalla, de orientación bética.

\section{Figura 1 \\ SITUACIÓN FÍSICA-HUMANA DE OLIVA}

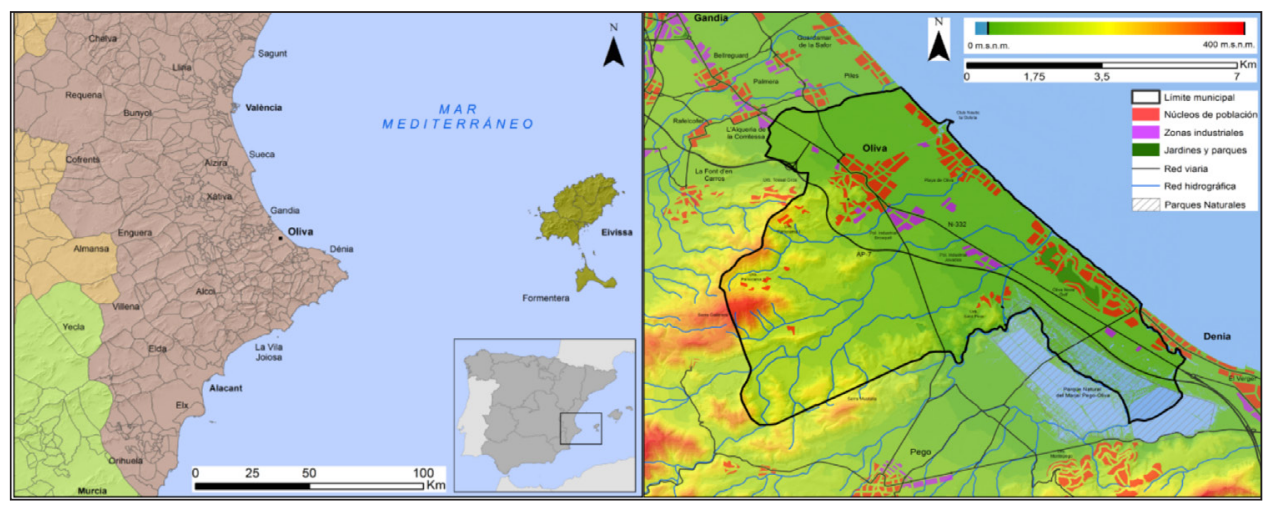

Fuente: elaboración propia. A partir del MDE 05 y Cartografía Offline de la Comunitat Valenciana de l'Institut Cartografic Valencià (Derecha). 


\subsection{Contexto histórico}

Desde la segunda mitad del siglo XX, como consecuencia de la transformación económica después de la Segunda Guerra Mundial (Arrighi, 1994; Harvey 1985; 2000; 2005), se ha producido un acelerado crecimiento de las superficies urbanas en las principales ciudades americanas y europeas. Desde entonces, este crecimiento urbano se ha producido principalmente en la periferia de las grandes ciudades y, sobre todo, en las zonas litorales. En este momento histórico de fuerte cambio económico y social, la industria turística llegó a España. El Mediterráneo español devino un escenario privilegiado para la implantación de los principales motores de desarrollo económico: el turismo y la construcción (Gaja, 2012). Con el desarrollo progresivo de la actividad turística, el sector inmobiliario encontró grandes posibilidades de inversión y alta rentabilidad y poco a poco, la línea que separa las nuevas modalidades de turismo emergentes y el negocio inmobiliario se fue volviendo cada vez más borrosa (Pons y Rullan, 2014).

Si nos remontamos a los últimos cincuenta años de historia, podemos afirmar que el crecimiento económico de España ha estado íntimamente ligado al sector inmobiliario (Rodriguez, 2006). Las épocas de bonanza vividas en España desde mediados del siglo $\mathrm{XX}$ se han sustentado recurrentemente en la efervescencia de la actividad constructora (Góngoras, 2017), y han terminado en fuertes periodos de crisis y depresión que han tenido un gran impacto sobre las clases medias y trabajadoras.

Para comprender mejor la evolución de los usos del suelo durante el periodo de estudio, hay que fijarse en las políticas estatales de fomento del sector inmobiliario que, desde la segunda mitad del siglo XX, tanto han influido en la evolución de los usos del suelo. En general, en las áreas turísticas mediterráneas y las áreas metropolitanas de las grandes ciudades, podemos dividir el proceso de auge inmobiliario en tres momentos álgidos o booms inmobiliarios, durante los cuales la tendencia urbanizadora creciente solamente se ha visto interrumpida por periodos de recesión económica (crisis del petróleo del 1973; crisis económica del 1993; estallido de la burbuja inmobiliaria de 2007) (Yrigoy, 2013; Llurdés-Coit et al., 2015; Rusca-Mestre et al., 2017).

Antes del primer boom inmobiliario España se encontraba en un periodo de autarquía franquista (1939-1950), que se caracterizó por la depresión, el cierre al exterior, la escasez de todo tipo de bienes y la interrupción drástica del proceso de modernización iniciado por el gobierno de la Segunda República (García-Delgado, 1995). En materia de suelo, esta época se caracterizó por la infraproducción de vivienda que dejó un panorama desolador (Gaja, 2005).

El final de esta etapa se produce a finales de la década de los cincuenta, con la vacilante liberalización y apertura al exterior del régimen. A partir de la promulgación de la Ley del Suelo de 1956 el urbanismo pasó a ser entendido un conjunto de facultades inherentes al derecho del propietario a convertirse en una función pública en la que prevalecía el "interés general" (García-Delgado, 1995). En realidad, el "interés” que prevalecía era el de unos cuantos promotores inmobiliarios afines al régimen.

El fin del desarrollismo vino marcado por la fuerte crisis del petróleo de 1973, que afectó gravemente a la economía española. Durante la Transición política (1975-1986) se vivió además la crisis de 1979, a las que se sumó la inestabilidad política. 
A continuación, llegó el Segundo boom inmobiliario (1986-1991), durante el cual el sector de la construcción entró en una fase expansiva. Para liderar la recuperación económica el gobierno socialista eligió el sector de la construcción, ya que era capaz de movilizar a mucha mano de obra. El Real Decreto-Ley 2/1985, también llamado Decreto Boyer, tenía como objetivo incrementar la compra de obras de nueva construcción, dar salida a las casas desocupadas mediante la liberalización del arrendamiento y estimular la inversión patrimonial. Durante este período de boom inmobiliario la demanda de segundas residencias en localidades litorales y en áreas de descongestión de las grandes ciudades fue notable. Fue en este momento cuando comenzó a desarrollarse el urbanismo expansivo en España. Esta forma de urbanismo ha sido ampliamente estudiada en diferentes áreas del mundo bajo el nombre de urban sprawl o urbanismo expansivo (Bruegman, 2005; European Environment Agency, 2006; Ewing et al., 2002; Ewing, 1997; Fulton et al., 2001; Galster et al., 2001; Lopez y Hynes, 2003). Este tipo de edificación basado en la baja densidad residencial supone un elevado coste económico en infraestructuras (viarias, alcantarillado, luz, etc.) que disfrutan solo unos pocos (Burriel, 2008; Membrado-Tena, 2013) y además tiene unos elevados costes desde el punto de vista ambiental.

Tras un corto periodo de crisis (1992-1996), derivado en parte del endeudamiento estatal ligado a los grandes eventos de 1992, dio comienzo el Tercer boom inmobiliario (19972007). Este fue el momento de máxima expansión del sector inmobiliario en España, que derivó en el desarrollo de una hiperurbanización, cuyo peor efecto a largo plazo será el agravamiento de la crisis ecológica (Gaja, 2005).

El exceso de producción inmobiliaria se puede ilustrar con datos: el boom inmobiliario alcanzó su punto máximo en 2006, año en que se construyeron más viviendas en España que en la suma de Italia, Reino Unido y Alemania, tres estados más poblados y ricos que el nuestro (Membrado-Tena, 2015). El gran incremento de viviendas en España durante este Tercer boom inmobiliario se puede explicar por dos factores principales. El primero es que, como miembro de la zona euro desde su creación en 1999, España disfrutó de los beneficios de formar parte de una divisa considerada fuerte y segura (Romero, 2010). De esta forma fue fácil para los bancos y empresas obtener créditos en el extranjero. El segundo factor fue la aprobación en 1998 de una nueva Ley del Suelo, que permitía que cualquier suelo no protegido fuera edificable (Rullán, 2011). La falta de un marco regulatorio adecuado permitió a los promotores privados construir tanto como quisieron. Ni las autoridades autonómicas ni estatales pudieron controlar este desarrollo urbano promovido por los municipios y por los intereses privados. Ni siquiera fueron capaces de atenuar su impacto en la sostenibilidad territorial (Burriel, 2008). Lo ocurrido durante 1996-2007 puede parecer un infortunio imprevisible y catastrófico causado por fuerzas del "mercado" pero no fue así. Fue causa de unas políticas que tenían un objetivo común: el crecimiento, el desarrollo del sector inmobiliario y el aumento de la producción, sin que importara el coste a pagar por ello (Gaja, 2012)

La situación cambió drásticamente cuando las líneas de crédito se cortaron a mediados de 2007 debido a la crisis financiera internacional (Membrado-Tena, 2013). En ese momento explotó la burbuja inmobiliaria, y se inició una crisis económica de la cual, diez años después, todavía no se ha salido. Aunque el descenso del paro y los índices macroeconómicos parecen indicar el inicio de la recuperación económica, la realidad de muchas familias españolas es muy diferente. 
A esta concatenación de factores económicos y hechos históricos debe sumarse la aportación al "boom" de las causas de orden urbanístico. En el caso de la Comunitat Valenciana, con una gran singularidad, la aprobación de la Ley Reguladora de la Actividad Urbanística (LRAU) en 1994. Esta ley se fundamentaba en la idea de que el terrateniente suponía un obstáculo que frenaba la actividad urbanística, tratándolo de residuo feudal incapaz para la acción empresarial. La LOTUP introducía por primera vez la figura del "agente urbanizador". Con la premisa de "modernizar el sector" y desbloquear el suelo de los terratenientes se rompió un principio secular: el del ius Aedificandi, es decir, la atribución en exclusiva al propietario del suelo de la potestad de edificar (Gaja, 2012) o en su caso, de no hacerlo.

Esta ley permitía que el "agente urbanizador" realizara las obras de urbanización sin ni siquiera disponer de propiedad alguna, con el único requisito de la presentación y aprobación de un proyecto denominado Programa de Actuación Integrada (PAI) y su posterior nombramiento por parte de los ayuntamientos. Este procedimiento dejaba completamente desprotegidos a los propietarios del suelo, que apenas tenían voz a la hora de decidir sobre sus terrenos y anteponía el beneficio del sector privado frente al servicio público. Este cambio en las reglas del juego refleja perfectamente las políticas neoliberales aplicadas en la Comunitat Valenciana, donde la Administración Pública abandonaba sus responsabilidades y dejaba al mercado a cargo de la acción urbanística.

\section{METODOLOGÍA}

Para analizar la evolución de los usos del suelo en Oliva hemos utilizado una tipología de investigación de métodos mixtos (Membrado-Tena, 2017). Por una parte, utilizamos un enfoque cuantitativo que se apoya en herramientas SIG para la clasificación, fotointerpretación y cuantificación de los usos del suelo. Este procedimiento metodológico se ha mostrado como una herramienta adecuada para estudiar los cambios en los usos del suelo (Valera et al., 2007). De forma complementaria se utilizan técnicas cualitativas que incluyen la bibliografía consultada, el trabajo de campo, la observación y percepción espontánea e intuitiva y el análisis crítico de las formas y modelos hallados sobre el terreno.

\subsection{Clasificación utilizada}

En primer lugar, se han definido las características de la clasificación utilizada para determinar los usos del suelo. La clasificación utilizada para este trabajo está inspirada en la clasificación de CORINE Land Cover, aunque la hemos alterado ligeramente para adaptarla a los objetivos de este trabajo. El proyecto CORINE, dirigido por la Agencia Europea de Medio Ambiente, tiene un nivel de detalle moderado. Dicha información presenta varios problemas que derivan principalmente de su baja resolución espacial (EEA, 2002): su unidad mínima de representación es de 25 ha para elementos poligonales y de 100 m para los lineales. Además, la clasificación de los tipos de coberturas es válida para todo el territorio europeo, lo que la hace apta para estudios a escala regional pero no para una escala municipal. 
Tabla 1

CARACTERÍSTICAS Y NOMENCLATURA DE LA CLASIFICACIÓN DE LOS USOS DEL SUELO UTILIZADA

\begin{tabular}{|c|c|c|c|}
\hline $\begin{array}{c}\text { Código } \\
\text { CORINE } \\
\text { (Nivel 3) }\end{array}$ & Grupo & Nomenclatura de la clasificación utilizada & $\begin{array}{l}\text { Unidad mínima } \\
\text { de digitalización }\end{array}$ \\
\hline 111 & \multirow{8}{*}{$\begin{array}{l}\text { Superficies } \\
\text { artificiales }\end{array}$} & TEJIDO URBANO CONTÍNUO & 2.5 ha. \\
\hline 112 & & TEJIDO URBANO DISCONTÍNUO * & 2.5 ha. \\
\hline 121 & & INDUSTRIAL Y COMERCIAL & 2.5 ha. \\
\hline 122 & & $\begin{array}{l}\text { RED VIARIA, FERROVIARIA Y } \\
\text { ASOCIADOS }\end{array}$ & 5 ha. / $100 \mathrm{~m}$ \\
\hline 123 & & ZONAS PORTUARIAS & 5 ha. \\
\hline 131 & & EXTRACCIÓN MINERA & 5 ha. \\
\hline 133 & & ZONAS EN CONSTRUCCIÓN & 2.5 ha. \\
\hline 142 & & INST. DEPORTIVAS Y RECREATIVAS & 2.5 ha. \\
\hline 212 & \multirow{4}{*}{$\begin{array}{l}\text { Superficies } \\
\text { agrícolas }\end{array}$} & TIERRAS DE LABOR DE REGADIO & 10 ha. \\
\hline 213 & & ARROZALES & 10 ha. \\
\hline- & & NARANJOS & 10 ha. \\
\hline- & & OTROS FRUTALES & 10 ha. \\
\hline 312 & \multirow{7}{*}{$\begin{array}{c}\text { Superficies } \\
\text { naturales } \\
\text { y espacios } \\
\text { abiertos }\end{array}$} & BOSQUE DE CONÍFERAS & 10 ha. \\
\hline 323 & & VEGETACIÓN ESCLERÓFILA & 10 ha. \\
\hline 331 & & PLAYAS Y DUNAS * & 10 ha. $/ 100 \mathrm{~m}$ \\
\hline 411 & & HUMEDALES Y ZONAS PANTANOSAS & 10 ha. \\
\hline 511 & & RIOS Y CAUCES PERMANENTES & 5 ha. / $100 \mathrm{~m}$ \\
\hline 513 & & RAMBLAS Y BARRANCOS * & 5 ha. $/ 100 \mathrm{~m}$ \\
\hline 523 & & MAR Y OCÉANO & 5 ha. \\
\hline
\end{tabular}

Las categorías naranjos y otros frutales no tienen código. Esto se debe a que son categorías nuevas que no aparecen en la clasificación oficial de CORINE. Estos dos tipos de cobertura están incluidos dentro de la categoría frutales de CORINE, pero debido a la gran importancia que tiene el cultivo de naranjos en el territorio estudiado, se ha considerado oportuno separarla de la categoría 222 (frutales) de CORINE, quedando por una parte, naranjos y por otra parte, otros frutales. En realidad, esta segunda categoría se reduce a cultivos arbóreos de secano, principalmente algarrobos y en menor medida olivos, como veremos en el apartado de resultados.

Las categorías marcadas con el símbolo $(*)$ son categorías que, aunque aparecen en CORINE con el mismo nombre, para este trabajo, han sufrido alguna modificación o surgen de la división, en dos, de una categoría de CORINE. En el caso de la categoría Tejido 
Urbano Discontinuo, aunque en CORINE corresponde a viviendas, calles, parques y áreas con vegetación que ocupan $50-80 \%$ de la superficie, en este caso se ha considerado Tejido Urbano Discontinuo a las superficies que contienen entre 30-70 \% de estos usos, para representar el fenómeno de dispersión de viviendas fuera de suelo urbano.

\section{Figura 2}

\section{SUPERFICIES CORRESPONDIENTES A TEJIDO URBANO DISCONTINUO (IZQUIERDA) Y TEJIDO URBANO CONTINUO (DERECHA)}

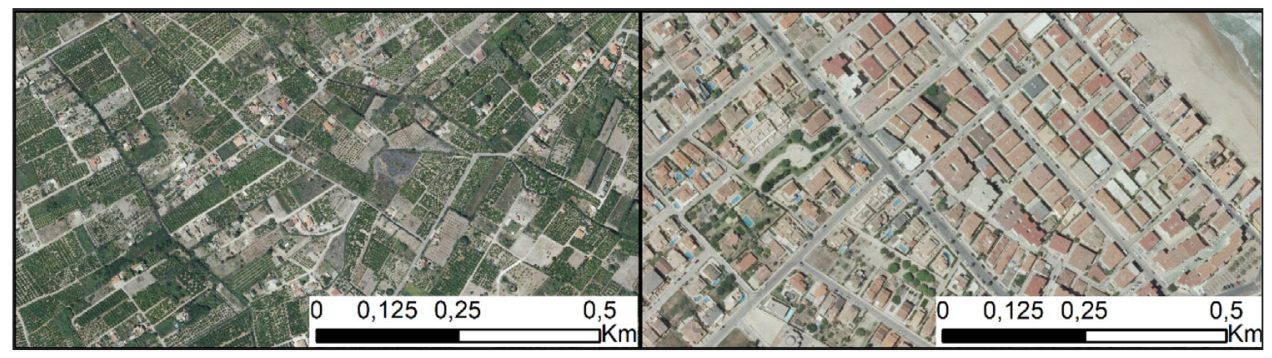

Fuente: elaboración propia a partir de la ortofoto PNOA de máxima actualidad del IGN.

\subsection{Procesamiento SIG}

Para la elaboración de la cartografía de usos del suelo se ha utilizado el software ESRI ArcGIS en su versión 10.4.1. Con él se ha realizado la georreferenciación y fotointerpretación del Vuelo Americano Serie B del año 1956-1957 a escala 1:33.000, del Vuelo Valenciano del 1991 a escala 1:25.000 y de la Ortofoto PNOA de 2014-2015. El datum geodésico utilizado es el ETRS89 Huso 30 N (European Terrestrian Reference System 1989).

Las diferentes hojas que componen el Vuelo Americano del 1956 y el Vuelo Valenciano del 1991 se han georreferenciado mediante la herramienta Georeferencing de ArcMap sobre la Ortofoto PNOA de 2015 disponible a través de la web del Instituto Geográfico Nacional. Para ello se han establecido una serie de puntos de control (entre 3 y 5 por hoja) con los que se han posicionado cada una de las imágenes. Una vez georreferenciados cada uno de los fotogramas que engloban el término municipal, se han consolidado formando un mosaico único con la herramienta Mosaic to new raster de ArcToolbox, obteniendo finalmente tres ortofotos correspondientes a cada uno de los años de estudio. Después se ha comprobado que las tres fotografías aéreas se disponen perfectamente superpuestas y se ha recortado según el término municipal con la herramienta Extract by mask de ArcToolbox.

La capa vectorial que marca el polígono que forma el término municipal se ha obtenido a partir del mapa comarcal del cual se ha extraído el término de Oliva. Este polígono ha sido la capa de referencia para recortar las ortofotos y la base para la digitalización de los usos del suelo.

Una vez completado este proceso se ha realizado la fotointerpretación. Se han digitalizado los usos correspondientes al año 1956. Para ello, en primer lugar, se ha creado una primera capa lineal en la que se han marcado con la mayor precisión posible los 


\section{Figura 3 \\ MOSAICOS DE LOS FOTOGRAMAS GEORREFERENCIADOS DE CADA UNO DE LOS VUELOS UTILIZADOS}

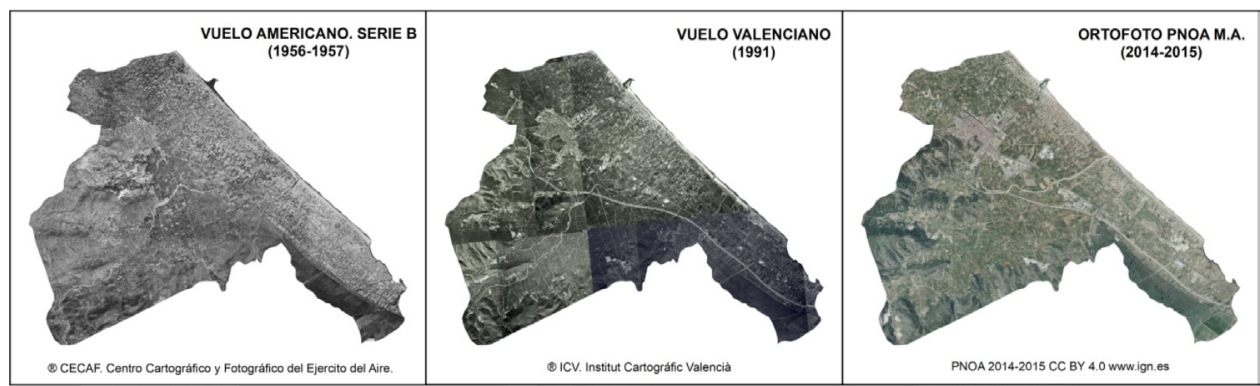

Fuente: elaboración propia.

principales usos lineales (carreteras, caminos, ríos, etc.). Una vez marcados se ha creado un área de influencia utilizando la herramienta Buffer con distancias diferentes para autopista, carretera, calle o río. De esta manera obtenemos polígonos lineales de diversas medidas. Después se han modificado manualmente los vértices de la capa resultante para obtener mayor exactitud. Esta corrección ha sido muy significativa en el caso de los ríos, ya que generalmente no mantienen un lecho constante, sino que tienen un ancho variable a lo largo de su cauce. En el caso de las carreteras y caminos la corrección necesaria ha sido mínima. A continuación, y con todos los usos lineales dibujados, mediante la herramienta Clip se ha cortado el polígono del término municipal a partir de la capa creada anteriormente y que contiene los usos lineales. Es importante el correcto uso de esta herramienta para evitar que se creen polígonos superpuestos y que, por tanto, no se incremente la superficie total.

Después se han definido el resto de usos mediante la herramienta Cut polygon; cortando el polígono que forma el término municipal en unidades más pequeñas. Para asegurar que cada polígono supera la unidad mínima de digitalización, se ha utilizado la herramienta de medición de ArcGIS (Measure) durante todo el proceso. Así se asegura que la cartografía cumple las características que la definen.

Una vez completada la digitalización para el polígono correspondiente al año 1956, se ha duplicado la capa y sobre esta, se ha realizado la digitalización para el año 1991 siguiendo el mismo proceso. Una vez completado este se ha realizado el mismo procedimiento para el año 2015. De forma simultánea al proceso de digitalización se ha introducido en la tabla de atributos el código correspondiente a cada uso.

\section{RESULTADOS}

A continuación, se presentan los resultados obtenidos para cada categoría y en cada uno de los años estudiados. Los resultados se han presentado tanto en hectáreas como en porcentaje sobre el total del término municipal que ocupa cada categoría. 
Tabla 2

RESUMEN DE LOS RESULTADOS OBTENIDOS EN PORCENTAJE Y SUPERFICIE (HA.) POR GRUPOS DE CATEGORÍAS

\begin{tabular}{|c|c|c|c|c|c|c|}
\hline \multirow[b]{2}{*}{ Usos del suelo } & \multicolumn{2}{|l|}{1956} & \multicolumn{2}{|c|}{1991} & \multicolumn{2}{|c|}{2015} \\
\hline & $\begin{array}{l}\text { Superficie } \\
\text { (ha.) }\end{array}$ & $\%$ & $\begin{array}{l}\text { Superficie } \\
\text { (ha.) }\end{array}$ & $\%$ & $\begin{array}{l}\text { Superficie } \\
\text { (ha.) }\end{array}$ & $\%$ \\
\hline Superficies artificiales & 132 & 2.2 & 737 & 12.3 & 1267 & 21.2 \\
\hline Superficies agrícolas & 4869 & 81.6 & 3477 & 58.2 & 2929 & 49 \\
\hline $\begin{array}{l}\text { Superficies naturales y espacios } \\
\text { abiertos }\end{array}$ & 965 & 16.2 & 1763 & 29.5 & 1780 & 29.8 \\
\hline
\end{tabular}

Tabla 3

RESUMEN DE LOS RESULRADOS OBTENIDOS EN PORCENTAJE Y SUPERFICE (HA.) POR CATEGORÍAS

\begin{tabular}{|c|c|c|c|c|c|c|}
\hline \multirow{2}{*}{ Usos del suelo } & \multicolumn{2}{|c|}{$\mathbf{1 9 5 6}$} & \multicolumn{2}{c|}{$\mathbf{1 9 9 1}$} & \multicolumn{2}{c|}{$\mathbf{2 0 1 5}$} \\
\cline { 2 - 7 } & $\begin{array}{c}\text { Superficie } \\
\text { (ha.) }\end{array}$ & $\mathbf{\%}$ & $\begin{array}{c}\text { Superficie } \\
\text { (ha.) }\end{array}$ & $\mathbf{\%}$ & $\begin{array}{c}\text { Superficie } \\
\text { (ha.) }\end{array}$ & \% \\
\hline TEJIDO URBANO CONTINUO & 62 & 1 & 151 & 2.5 & 391 & 6.5 \\
\hline TEJIDO URBANO DISCONTINUO & - & 0 & 176 & 2.9 & 480 & 8 \\
\hline INDUSTRIAL Y COMERCIAL & 5 & 0.1 & 42 & 0.7 & 126 & 2.1 \\
\hline RED VIARIA, FERROVIARIA Y AS. & 52 & 0.9 & 97 & 1.6 & 98 & 1.6 \\
\hline ZONAS PORTUARIAS & - & 0 & 9 & 0.2 & 9 & 0.2 \\
\hline EXTRACCIÓN MINERA & 9 & 0.2 & 8 & 0.1 & 8 & 0.1 \\
\hline ZONAS EN CONSTRUCCIÓN & 4 & 0.1 & 245 & 4.1 & 65 & 1.1 \\
\hline INS. DEPORTIVAS Y RECREATIVAS & - & 0 & 9 & 0.2 & 90 & 1.5 \\
\hline TIERRAS DE LABOR DE REGADÍO & 229 & 3.8 & - & 0 & - & 0 \\
\hline ARROZALES & 378 & 6.3 & - & 0 & - & 0 \\
\hline NARANJOS & 3081 & 51.6 & 3477 & 58.2 & 2929 & 49 \\
\hline OTROS FRUTALES & 1181 & 19.8 & - & 0 & - & 0 \\
\hline BOSQUE DE CONÍFERAS & 603 & 10.1 & 1084 & 18.1 & 1087 & 18.2 \\
\hline VEGETACIÓN ESCLERÓFILA & 207 & 3.5 & 226 & 3.8 & 223 & 3.7 \\
\hline PLAYAS Y DUNAS & 87 & 1.5 & 83 & 1.4 & 83 & 1.4 \\
\hline HUMEDALES Y ZONAS & - & 0 & 303 & 5.1 & 303 & 5.1 \\
\hline PANTANOSA & 34 & 0.6 & 33 & 0.6 & 33 & 0.6 \\
\hline RIOS Y CAUCES PERMANENTES & 34 & 0.6 & 34 & 0.6 & 51 & 0.9 \\
\hline MAMBLAS Y BARRANCOS & 10 & 0.2 & - & 0 & - & 0 \\
\hline
\end{tabular}


A priori, los resultados más llamativos son los referentes a las superficies artificiales, que han experimentado un crecimiento del $866 \%$ respecto a los valores de 1956 . Dentro de este grupo, las categorías que han experimentado mayor crecimiento son tejido urbano discontinио у tejido urbano continuo respectivamente. También podemos observar que algunos usos existentes en el 1956 han desaparecido con el paso de los años (arrozales, otros frutales, y tierras de labor de regadio) y otras que no existían han ido apareciendo (instalaciones deportivas y recreativas, humedales y zonas pantanosas y zonas portuarias).

Por último, otro dato que reflejan los resultados es la gran importancia que ha tenido el cultivo citrícola para el municipio. El cultivo de naranjos ha llegado a ocupar el 58\% de la superficie del término municipal en 1991, aunque su tendencia en las dos últimas décadas ha ido en descenso.

\section{Tabla 4}

TASAS DE CRECIMIENTO MEDIO ANUAL DE CADA GRUPO DE CATEGORÍAS

\begin{tabular}{|l|c|c|c|c|c|c|}
\hline & \multicolumn{2}{|c|}{$\mathbf{1 9 5 6 - 1 9 9 1}$} & \multicolumn{2}{c|}{$1991-2015$} & \multicolumn{2}{c|}{ 1956-2015 } \\
\cline { 2 - 7 } & $\begin{array}{c}\text { Increm. } \\
\text { (ha.) }\end{array}$ & $\begin{array}{c}\text { Crecim. } \\
\text { anual }\end{array}$ & $\begin{array}{c}\text { Increm. } \\
\text { (ha.) }\end{array}$ & $\begin{array}{c}\text { Crecim. } \\
\text { anual }\end{array}$ & $\begin{array}{c}\text { Increm. } \\
\text { (ha.) }\end{array}$ & $\begin{array}{c}\text { Crecim. } \\
\text { anual }\end{array}$ \\
\hline Superficies artificiales & 605 & $5 \%$ & 530 & $2.3 \%$ & 1135 & $3.9 \%$ \\
\hline Superficies agrícolas & -1392 & $-1 \%$ & -548 & $0.7 \%$ & -1940 & $-0.86 \%$ \\
\hline $\begin{array}{l}\text { Superficies naturales y } \\
\text { espacios abiertos }\end{array}$ & 798 & $1.74 \%$ & 17 & $0.04 \%$ & 815 & $1.04 \%$ \\
\hline
\end{tabular}

Si tratamos de comparar los resultados obtenidos con las tasas de crecimiento del conjunto de los municipios litorales de la Comunitat Valenciana obtenidos por Zornoza (2013) observamos que no son fácilmente comparables. Aunque la tasa de crecimiento anual de las superficies artificiales en nuestro periodo de estudio (3,9\% anual entre 1956-2015) es mayor que las obtenidas por la autora (2,81\% anual entre 1987-2005), no presenta una diferencia tan destacada. Esto se debe a que el periodo estudiado entre 1987 y 2005 fue un periodo de gran actividad, mientras que en nuestro estudio se considera un periodo mucho más amplio que contiene grandes momentos de crisis en los que el crecimiento fue prácticamente nulo.

No obstante, podemos inferir la tasa de crecimiento anual de superficies artificiales en la franja litoral (0-500 m. desde la línea de costa) en el periodo 1987-2005 en Oliva a partir de los datos de Prieto (2013). Según sus resultados, Oliva experimentó un índice de crecimiento de superficies artificiales de 667 (considerando la superficie de $1987=$ 100). Esto significa que las superficies artificiales se multiplicaron por 6,7 en este periodo.

Estos datos implican que la tasa de crecimiento anual en Oliva fue del $11 \%$ entre los años 1987 y 2005 . Estos datos sí resultan significativamente mayores a los observados en la franja de 0-500 m. de los municipios litorales de la Comunitat Valenciana $(3,2 \%$ anual entre 1987-2005).

A continuación, se analizan los usos del suelo para cada uno de los años de estudio y su distribución espacial: 


\section{Figura 4}

\section{USOS DEL SUELO EN OLIVA EN 1956}

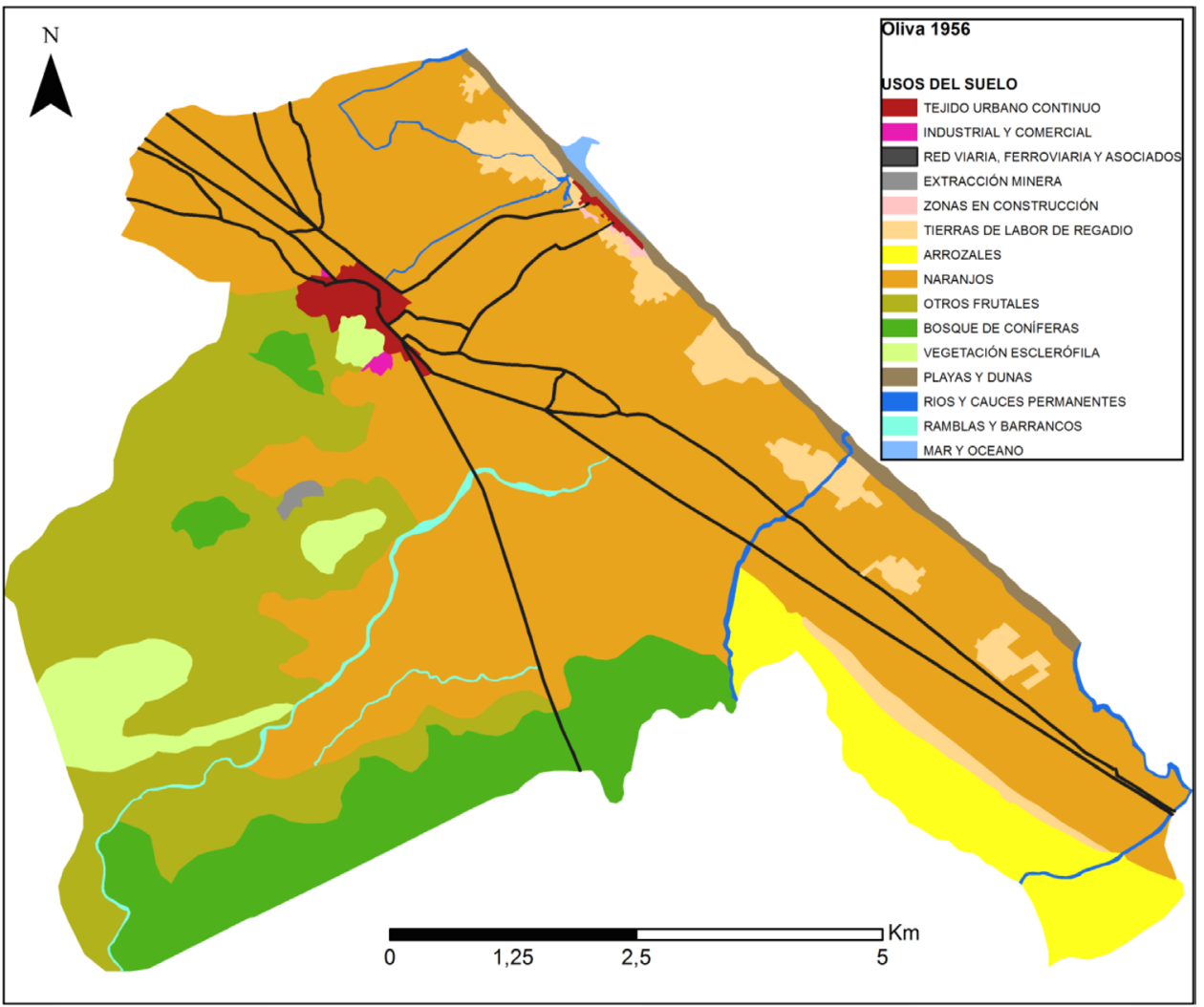

Fuente: Elaboración propia.

\subsection{Usos del suelo en 1956}

En el 1956 la mayoría del término municipal estaba dedicado al uso agrícola (81\%). La llanura litoral de la que hemos hablado en el apartado de introducción estaba ocupada por el cultivo de naranjos y en menor medida por tierras de labor de regadío. El cultivo de la naranja era el predominante, llegando a ocupar el 51\%; en cambio, los cultivos hortícolas de regadío solo ocupan el $4 \%$. Muchas de las parcelas de huerta que observamos en el Vuelo Americano del 1956 no aparecen en nuestros resultados debido a que no superan la unidad mínima de digitalización. Pero la realidad es que se observan gran cantidad de parcelas de huerta (tierras de labor en regadio) entre los cultivos de naranjos. No obstante, sí aparecen masas de huerta representativas en la franja más próxima a la costa. Esta mayor 
densidad de tierras de labor de regadío en las zonas próximas a la costa no es casual, sino que obedece a factores climáticos. En esta zona más próxima a la costa, los vientos frescos de levante no son favorables para el cultivo citrícola y hacen que la fruta madure más tarde. Esta maduración tardía de la naranja hace que la tenga un valor de mercado menor, pues las naranjas que maduran más pronto se pagan a precios más altos.

Fuera de la llanura litoral, en las montañas, la categoría otros frutales dominaban el paisaje (20\%). Los frutales que ocupaban las montañas eran especies de secano, principalmente algarrobos y en menor medida olivos. Las montañas estaban abancaladas y cultivadas hasta donde la pendiente lo permitía. Por este motivo los bosques de coníferas solo ocupaban un $10 \%$ (la mayoría en la vertiente norte de la Serra Mustalla), lo que representa una superficie mucho menor que la que ocupan en la actualidad. También por este motivo, la vegetación esclerófila quedaba relegada a las zonas más altas e inaccesibles de las montañas o donde la pendiente no permitía la explotación agrícola.

El tejido urbano solamente ocupaba el $1 \%$ de la superficie del término municipal y se distribuía en dos núcleos: el núcleo tradicional y el poblado marítimo donde se pueden observar unas pequeñas zonas en construcción $(0,1 \%)$, que supusieron el principio de la expansión urbanística de la playa de Oliva. La actividad industrial era reducida y se disponía a las afueras del núcleo tradicional.

\subsection{Usos del suelo en 1991}

En el año 1991 se observa un notable crecimiento del tejido urbano con respecto a los valores de 1956, ya que llega a ocupar el 5,5\%. El tejido urbano continuo ocupa el $2,5 \%$ y el tejido urbano discontinuo ocupa el $3 \%$ de la superficie del término municipal. Este crecimiento se produce principalmente en la franja litoral, aunque también se amplía el núcleo tradicional y se crean las pequeñas urbanizaciones de montaña Tossal Gros, Panorama I y Panorama II.

En este momento, Oliva se encuentra en un periodo de expansión. Además del tejido urbano ya consolidado observamos nuevas zonas en construcción. La que más destaca por su tamaño es la de Oliva Nova, que ya ocupaba el $3 \%$ de la superficie total del municipio. La construcción de esta urbanización supuso un punto de inflexión en la forma de urbanizar y de ocupar el litoral del municipio. También se observan otras zonas en construcción como el Sector 5 en la playa y l'Hort de la Bosca como expansión del núcleo tradicional. Este crecimiento urbano se produjo mayoritariamente a costa de las zonas de cultivo de naranjos y tierras de labor de regadio.

Destaca también la proliferación de distintas zonas de uso industrial y comercial $(0,7 \%)$ en las inmediaciones de la N-332, tanto al norte como al sur del municipio. En la imagen del 1991 se puede observar ya la Autopista 7 y el Puerto deportivo la Goleta que data del año 1982.

A pesar de que las nuevas zonas urbanas se han construido donde anteriormente había cultivo de naranjos, estos han crecido con respecto a valores de 1956 (52\% en 1956; $58 \%$ en 1991). Este crecimiento se produjo hacia el oeste, ocupando la parte baja de las montañas. Esto se debe a que entre el 1956 y el 1991 se produjo el momento de máximo esplendor de la economía citrícola. Debido a las cuantiosas ganancias que generaba la 


\section{Figura 5 \\ USOS DEL SUELO EN OLIVA EN 1991}

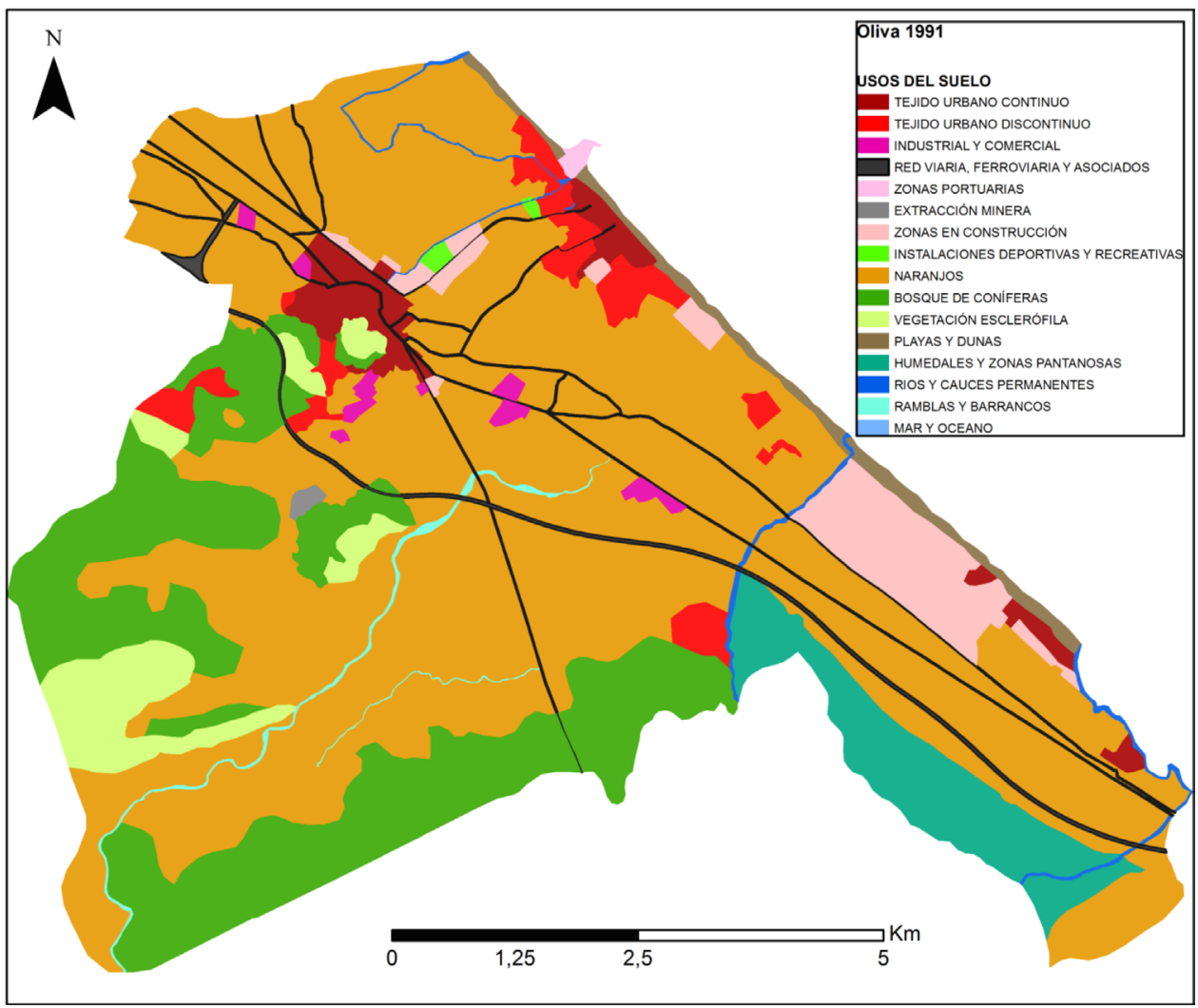

Fuente: Elaboración propia.

naranja y al bajo coste de la mano de obra, durante la década de 1980, muchos agricultores decidieron abancalar zonas de montaña y acondicionarlas para el cultivo de la naranja. En esta época estas inversiones resultaban rentables y se amortizaban en pocos años ya que la naranja de estas zonas era muy temprana y se pagaba a un precio muy caro. Por este motivo desaparecen los cultivos de secano y las tierras de labor para dejar paso al cultivo de cítricos.

Al igual que otros frutales y las tierras de labor de regadio, la producción de arroz también ha desaparecido. En el Marjal, ya no encontramos arrozales, sino que aparece como una zona húmeda tal y como la conocemos actualmente (5,1\% en 1991). El carrizal era, al igual que en la actualidad, la vegetación dominante del Marjal, con especies como Nasturium officinale y Paspalum paspalodes. También podemos encontrar nenúfares de agua como Nymphea alba. En los márgenes de las acequias que atraviesan el marjal domina la Rubus ulmifolius. También encontramos especies exóticas como Arundo donax 
y Calystegia sepium. Resulta curiosa la presencia de Narcisus perezlarae, una especie endémica de la Península Ibérica y que cuenta con varias poblaciones alrededor del Marjal.

Gran parte de las zonas de montaña que en 1956 estaban ocupadas por algarrobos y olivos han sido sustituidas por bosque de coníferas (18,1\% en 1991). La vegetación presente en el año 1991 era prácticamente la misma que encontramos en la actualidad, resultado de un proceso degradativo por parte del hombre desde sus orígenes como agricultor y ganadero.

\subsection{Usos del suelo en 2015}

En el 2015 el suelo urbano ocupa el 14,6\% de la superficie del término municipal. El tejido urbano continuo supone el 6,5\%, frente al $8 \%$ del tejido urbano discontinuo. Este gran crecimiento del tejido urbano discontinuo se debe mayormente a la proliferación de viviendas ilegales en la zona litoral. Como se puede observar en la figura 6 el crecimiento urbanístico del municipio se ha localizado mayoritariamente sobre su extensa franja litoral. También destaca la ampliación de las áreas industriales y comerciales (2\%) que ya aparecían en el año 1991. El crecimiento de esta categoría se produce por las grandes inversiones que se producen a partir del año 2000 en el sector industrial. En el caso de Oliva el crecimiento de las zonas industriales se produce por ampliación de las zonas ya existentes y no como creación de nuevas islas industriales.

Las zonas deportivas y recreativas ocupan una superficie destacable del término municipal $(1,5 \%)$ debido, sobre todo, a la gran extensión que ocupan los campos de golf y el complejo ecuestre de Oliva Nova.

Por el contrario, las superficies agrícolas decrecen. La superficie dedicada al cultivo de naranjos se reduce hasta el $49 \%$. Aunque esta categoría sigue ocupando casi la mitad de la superficie del municipio, decrece con respecto a los valores del 1991. Esta disminución de superficie de naranjos se produce por el crecimiento del tejido urbano continuo y discontinuo y de las zonas industriales y comerciales. Además, en la ortofoto de 2015 podemos observar gran cantidad de cultivos citrícolas abandonados, aunque no aparecen en nuestros resultados por no superar la unidad mínima de digitalización. Este aumento de las parcelas en desuso es una manifestación clara de la pérdida de poder de sector citrícola en Oliva.

Las superficies naturales se mantienen con valores similares a los de 1991. El Marjal Pego-Oliva se mantiene con las mismas características que en 1991, por lo que respecta a los usos del suelo, pero con un mayor estado de conservación debido a los efectos de la aprobación del Decreto 70/1999, de 4 de mayo, del Gobierno Valenciano, por el que se aprobó el Plan de Ordenación de los Recursos Naturales del Marjal de Pego-Oliva. Actualmente las únicas explotaciones arroceras del marjal se encuentran en el término municipal de Pego, que comercializa su variedad bombón (denominación de origen del Parque Natural), mientras que toda la superficie del parque correspondiente a Oliva está protegida.

Por último, hay que destacar la presencia de la infraestructura de canalización de la Rambla de Gallinera. Aunque no tiene gran importancia a nivel cuantitativo sobre los usos del suelo, su construcción entre los años 2010 y 2013 supuso un paso importante en pro de solucionar los graves problemas de inundabilidad con los que lidia el municipio olivense. 
Figura 6

USOS DEL SUELO EN OLIVA EN 2015

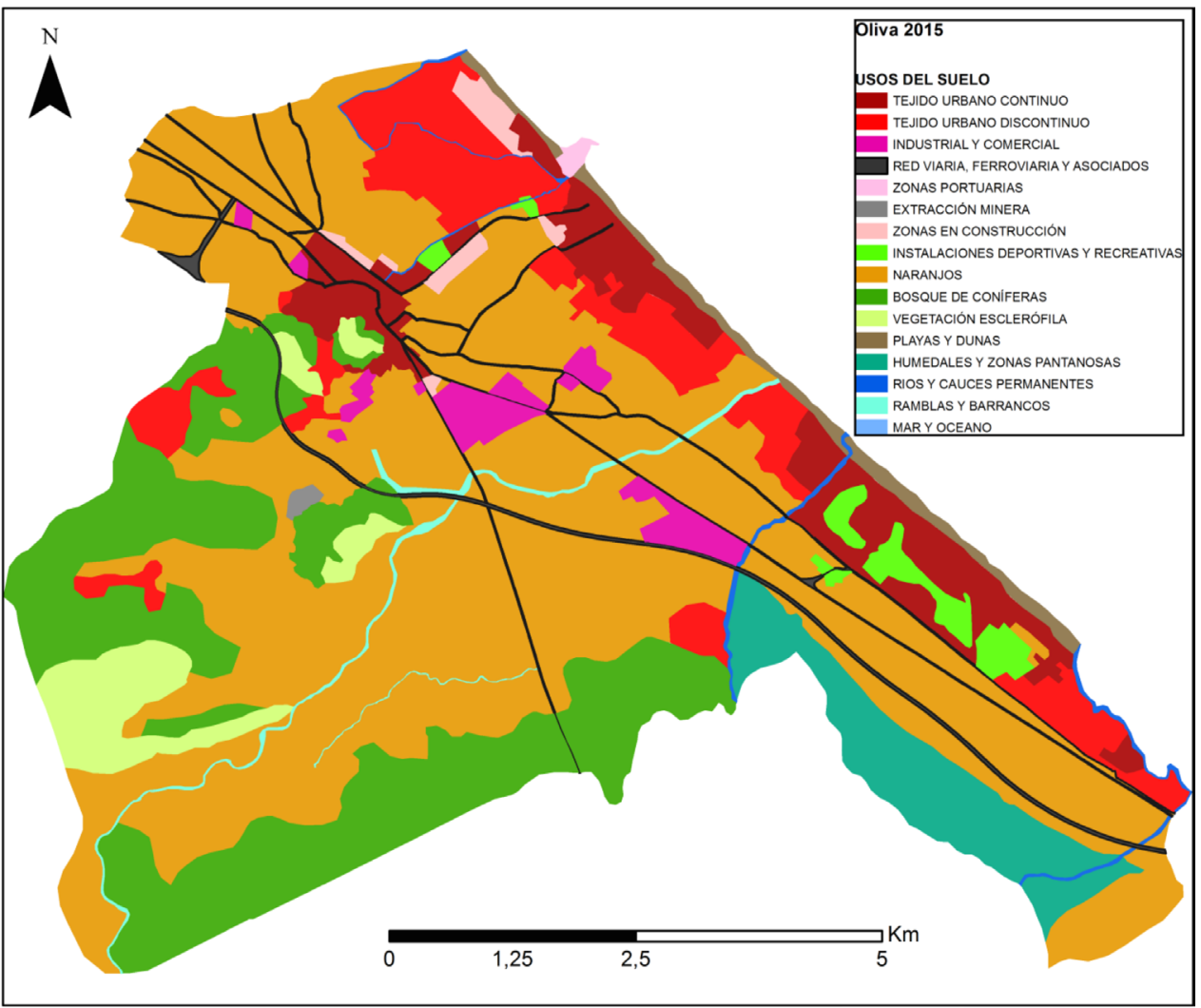

Fuente: Elaboración propia.

\section{DISCUSIÓN}

A partir de los resultados mostrados podemos analizar cuáles han sido los cambios en los usos del suelo y en las dinámicas territoriales del municipio olivense, así como sus causas, sus características y sus efectos.

\subsection{Principales cambios en las dinámicas territoriales}

El primer hecho remarcable inferido a partir de los resultados obtenidos es la importancia histórica de la agricultura y el progresivo abandono y sustitución de esta por usos artificiales, generalmente de carácter urbano. En 1956 Oliva era aún un área fundamentalmente rural en la cual la acción antrópica sobre el territorio se centraba en la explotación agrícola. En el caso de Oliva, esta intensa explotación agrícola ha tenido una gran importancia histórica. Sus características topográficas especialmente aptas para el cultivo, 
sus características edáficas, su alta disponibilidad de agua, y el hecho de que la comarca de La Safor sea una de las áreas más lluviosas del País Valenciano, han hecho de Oliva uno de los emporios de la economía citrícola de todo el país. Prueba de ello es el amplio patrimonio relacionado con el agua y la agricultura de la comarca de La Safor, que ha sido estudiado por Jorge Hermosilla (2005) en Los riegos de La Safor y La Valldigna. Agua, territorio y tradición.

El abandono generalizado de la agricultura citrícola no se ha producido solamente por la aparición de usos más rentables y su progresiva sustitución hacia usos artificiales, sino también por una serie de características estructurales, económicas y sociales que impiden la competitividad del sector. En primer lugar, la estructura minifundista (menor de 5 ha.) de las explotaciones no permite a los agricultores generar suficientes ingresos para seguir con la producción. Además, la estacionalidad propia de este tipo de cultivo ha llevado a los agricultores a buscar otras fuentes de ingresos durante el resto del año. En segundo lugar, el desarrollo económico iniciado en la década de 1960-1970, basado en el sector servicios, el sector de la construcción y el sector industrial, ha dejado a la agricultura en un escenario desfavorable. En este contexto económico y con un nivel de vida más alto, los agricultores abandonan los campos en busca de alternativas laborales más rentables. La tercera y última causa es la competencia con otros países con mano de obra más barata y por tanto, con menores costes de producción. Además, los avances tecnológicos han permitido a algunos países con plantaciones intensivas implantar nuevas técnicas que permiten cosechar un producto similar a un precio mucho más bajo. En cambio, estas técnicas no son viables para los campos de Oliva, caracterizados por su estructura minifundista.

A pesar de esto, en Oliva, sigue habiendo una gran superficie dedicada al cultivo de naranja. Por este motivo es lógico platearse la siguiente pregunta: ¿por qué los agricultores no abandonan definitivamente la naranja? Posiblemente la razón sea el factor cultural. Estos agricultores no desean abandonar lo que han hecho toda su vida, ni desean dejar perder el trabajo de tantas generaciones, aunque el beneficio económico sea mínimo o nulo. Además, en el contexto económico de crisis al cual nos enfrentamos desde hace ya diez años, muchas personas han visto sus antiguos cultivos como una pequeña oportunidad para generar algún ingreso y se han dedicado a ello, aunque solo sea a tiempo parcial. Posiblemente, con las futuras generaciones este arraigo cultural se irá perdiendo y los campos de naranjas acabarán por abandonarse.

No obstante, la importancia de la agricultura no reside solamente en el sector citrícola. Durante el periodo de posguerra y autarquía franquista, con unos niveles de escasez mayúsculos, la población olivense explotó sus tierras y utilizó más de tres cuartas partes de su superficie para el cultivo. Prácticamente, toda superficie susceptible de ser aprovechada para el cultivo de algún tipo de producto estaba dedicada a ello. El Marjal Pego-Oliva estaba dedicado en su totalidad al cultivo de arroz. Las zonas menos aptas para el cultivo de la naranja estaban dedicadas a la producción de productos de huerta como forma de autoabastecimiento y, en las montañas, los bancales eran ocupados por cultivos de secano que, aunque no proporcionaban un gran beneficio económico, en ese momento histórico eran una alternativa válida para combatir la hambruna.

El segundo hecho significativo es el cambio de modelo territorial hacia un modelo de ciudad dispersa y polinuclear con una alta ocupación del litoral. Aunque es innegable la 
importancia que ha tenido el turismo y las inversiones de capital extranjero desde Europa (Pons y Rullán, 2014) en este crecimiento urbanístico, cabe mencionar un elemento muy significativo que es el de la "moda de la segunda residencia". Aunque una parte del turismo olivense procede de países europeos, la mayoría de las nuevas construcciones van dirigidas a personas del propio municipio o de municipios cercanos, a personas de municipios interiores o incluso de otras comunidades españolas que buscan una zona tranquila donde pasar el verano fuera de los grandes epicentros turísticos como son Gandia y Dénia. Este turismo de tipo apartamento dedicado a la segunda residencia concuerda con la tipología general del País Valenciano en contraposición a otros modelos como el turismo de tipo hotel de Baleares (Gaja, 2012)

El fenómeno de expansión urbana se puede observar si comparamos el crecimiento de las superficies urbanas con el crecimiento demográfico del municipio (Tabla 5). El fenómeno del urban sprawl o urbanismo expansivo y la moda de las segundas residencias han hecho que la relación $\mathrm{m}^{2}$ /habitante se haya disparado. Para la elaboración de la siguiente tabla no se han contabilizado las superficies industriales como superficies urbanas. Si se hubiesen contabilizado los resultados se elevarían a 470 m²/hab. en 2015 .

Tabla 5

\section{RELACIÓN ENTRE EL CRECIMIENTO DE LAS SUPERFICIES URBANAS Y EL CRECIMIENTO DEMOGRÁFICO EN OLIVA}

\begin{tabular}{|c|c|c|c|}
\hline & $\mathbf{1 9 5 6}$ & $\mathbf{1 9 9 1}$ & $\mathbf{2 0 1 5}$ \\
\hline Superficies urbanas $\left(\mathrm{Km}^{2}\right)$ & 0.75 & 6.62 & 10.8 \\
\hline Habitantes (hab.) & ca. 15000 & ca. 20000 & ca. 27000 \\
\hline$\left(\mathbf{m}^{2} / \mathbf{h a b}.\right)$ & 50 & 330 & 380 \\
\hline
\end{tabular}

La posguerra y el periodo de autarquía franquista supusieron una profunda regresión económica que no comenzó a superarse hasta bien entrados los años cincuenta. En 1956 las superficies artificiales solo ocupaban el 2,6\% de la franja litoral (de 0 a $500 \mathrm{~m}$.). Con la aprobación de la Ley del Suelo del 1956, el Plan de Estabilización del 1959 y el auge inmobiliario desarrollista (1960-1973) comenzó a desarrollarse un modelo económico basado en la urbanización y la atracción turística. Este modelo fundado en el producto sol y playa supuso un crecimiento urbano notable en el litoral valenciano, sobre todo en las zonas más próximas al mar. No obstante, el alcance de este primer boom inmobiliario en Oliva fue menor que en otros municipios litorales. Durante este primer boom urbanístico se expandió el núcleo tradicional, el poblado marítimo y aparecieron otras pequeñas manchas urbanas en el litoral, que ocupaban solo una pequeña parte de la franja costera.

Durante el segundo boom inmobiliario (1986-1992) el sector de la construcción entró en una fase expansiva que supuso el primer gran auge urbanizador para Oliva. En el año 1991 las superficies urbanas y las que se encontraban en construcción ocupaban el 49,6\% de la franja litoral (de 0 a 500 m.). Este segundo boom inmobiliario sí que tuvo un impacto importante en el municipio. En este momento la playa de Oliva adquiere una gran popularidad como destino turístico. La construcción de la urbanización Oliva Nova y la 
llegada de inversiones extranjeras suponen un punto de inflexión en la ocupación urbana del litoral olivense. Gran parte de los edificios construidos son bloques de 2 o 3 plantas y viviendas unifamiliares. Durante este periodo de construcción se consolida un nuevo modelo basado en la baja densidad que responde a la demanda de la población de una segunda residencia. Esta segunda residencia está enteramente ligada a la época estival, en la cual los habitantes de Oliva, de municipios próximos, de otras comunidades autónomas o incluso turistas extranjeros buscan un alojamiento vacacional en una zona tranquila.

En el mapa de 2015 se muestran los efectos el tercer boom inmobiliario (1997-2007), el cual supuso el más extenso y veloz desarrollo urbanístico conocido jamás en España. Este tercer boom inmobiliario también afectó a Oliva y tuvo un alcance comparable al de 1986-1992 a pesar de la gran magnitud que tuvo aquel y la cantidad de oferta de vivienda que generó. En 2015 las superficies urbanas ocupaban el 75\% del suelo disponible en la franja litoral (de 0 a 500 m.). Estos valores son prácticamente los mismos que los que podemos encontrar en la actualidad debido a que desde el estallido de la burbuja inmobiliaria la actividad constructora se ha paralizado casi por completo. Cabe destacar la gran expansión del tejido urbano discontinuo que deriva en mayor parte de la proliferación de viviendas ilegales (en suelo no urbanizable) en la zona costera, sobre todo en la periferia de las zonas urbanas consolidadas. La falta de control de la administración local para evitar este tipo de prácticas ha sido el factor clave para entender esta expansión del tejido urbano discontinuo. Durante muchos años el Ayuntamiento de Oliva ha impuesto multas insignificantes a los propietarios sin obligación de demoler dichas construcciones. El pago de estas multas legitimaba de alguna manera a los propietarios para mantener la construcción. En este sentido, la administración local ha favorecido este tipo de prácticas manifestando su interés especulativo y favoreciendo un sistema incuestionablemente corrupto.

\subsection{Implicaciones del nuevo modelo territorial}

Este crecimiento urbanístico desmesurado durante este tercer boom inmobiliario, junto con una clara falta de planificación y reflexión territorial han tenido grandes consecuencias económicas, sociales y ambientales que se ven y se seguirán viendo reflejadas tanto a escala municipal como supramunicipal. El "tsunami urbanizador" (Gaja, 2008) es calificado hoy en día como insostenible y como una amenaza al desarrollo territorial futuro. No obstante, este error no es nuevo. Los planes desarrollistas de los años sesenta y setenta (Ezquiaga, 2003) ya hacían patentes las graves consecuencias de este tipo de planeamiento. Durante este tercer boom inmobiliario, en la Comunitat Valenciana, se ha producido una planificación urbanística residencial claramente desmesurada. La causa principal de esta cantidad de suelo urbanizable es que la planificación se ha realizado desde una óptica municipal, sin relación con la demanda efectiva de cada área territorial (Burriel, 2009), hecho que ha generado unos Planes Generales sobredimensionados. Oliva tiene claros ejemplos de este afán urbanizador con 23 ha. urbanizadas sin edificar en Playas Norte/Kiko, 7 ha. en Canyades, 4 ha. en Aigua Blanca IV y 13 ha. en Rabdells con aproximadamente la mitad de las parcelas sin edificar y la otra mitad con viviendas desocupadas. Estos datos que manejamos nos hacen pensar que, en caso de necesitarlo, el suelo urbanizado en Oliva es más que suficiente para cumplir las necesidades de, los 
próximos 20 años o al menos, hasta que la crisis ecológica nos golpee más duramente de lo que lo ha hecho la crisis económica.

En el caso de Oliva los impactos territoriales, derivados del enorme desarrollo urbanístico, se manifiestan a través de una serie de conflictos como los problemas de movilidad interna y externa, tanto por el crecimiento territorial desordenado como por la ineficiencia de la red primaria; el enorme impacto ambiental y paisajístico, sobre todo en el litoral; el altísimo consumo de recursos escasos como agua, suelo y energía; la fragmentación territorial e ineficiencia de la red de infraestructura verde; el incremento de la superficie urbana en zonas inundables (aumento del riesgo y la vulnerabilidad) y el incremento del gasto público e incapacidad de la administración para dotar de infraestructuras y servicios públicos para atender tal volumen residencial. A todo ello se le suma la gran dispersión de viviendas fuera de suelos urbanos, fruto de la permisibilidad del Ayuntamiento. Estas viviendas no disponen de red de alcantarillado por lo que suponen un riesgo por contaminación del suelo y las aguas.

Evidentemente, la crisis a la que hemos asistido en los últimos diez años ha paralizado gran parte de los planes urbanísticos de toda España. Con los planes que no se han llegado a culminar, los ayuntamientos españoles, en general, y el de Oliva, en particular, van a perder durante muchos años la iniciativa sobre la ordenación espacial del territorio (Burriel, 2009), pues los agentes urbanizadores han incumplido los plazos para urbanizar, edificar y han suprimido los compromisos adquiridos. Por otra parte, están los planes ya ejecutados. En este caso, ayuntamientos como el de Oliva, han recibido espacios urbanizados, pero sin demanda de construcción, con el alto coste de mantenimiento que supone (ejemplos: Playas Norte/Kiko, Canyades, Rabdells y Aigua Blanca IV, nombrados anteriormente). En este caso el ayuntamiento no recibe ingresos vía impuestos y los propietarios de los suelos, además de haber pagado los costes de urbanización, tienen que pagar el mantenimiento e impuestos más altos.

Aunque esta tendencia urbanizadora ha sido común a todos los municipios litorales del Mediterráneo español, el caso de Oliva es excepcional, sobre todo por lo que respecta al segundo y tercer boom inmobiliario. De hecho, Oliva es el municipio español de la vertiente mediterránea con el mayor crecimiento urbanístico en la franja litoral entre los años 1987 y 2005 (Prieto, 2013). Este hecho lo sitúa como uno de los municipios más insostenibles del país y le ha hecho ganar la fama del municipio mediterráneo español que más ha destruido su patrimonio natural (Marcos et al., 2013). A pesar de este desprestigio, hay que reconocer, sin embargo, que Oliva conserva gran parte de su patrimonio natural, del cual destacan sus playas y dunas. Cuenta con más de 6,5 kilómetros de cordón dunar que en algunos tramos supera los 150 metros de holgura. El sistema dunar de Oliva es uno de los mejor conservados de la costa valenciana, junto con el de la playa del Saler (València) y la de l'Ahuir (Gandia). Además, la baja edificabilidad con la que se ha urbanizado en la playa de Oliva, con solo 1 o 2 alturas, crea un espacio urbano litoral que genera un menor impacto paisajístico y visual con respecto a otros municipios costeros.

La expansión del espacio construido en todo el litoral valenciano con el predominio de modelos de baja densidad, y la creación de nuevas áreas urbanas e interurbanas y sin una planificación sostenible del territorio, ha producido, además del grave impacto ambiental y consumo de recursos, una notable ineficiencia del planeamiento municipal y 
una necesidad urgente de abordar otras escalas de planificación (Salom, 2010). A pesar de esta creciente demanda de perspectivas superiores de planificación, sigue imperando la visión municipalista. El motivo de la óptica de planificación es que hasta el año 2011, con la aprobación de la Estrategia Territorial de la Comunitat Valenciana ${ }^{2}$, no se contaba con unas directrices globales de desarrollo para todo el territorio valenciano.

Actualmente, con la Estrategia Territorial de la Comunitat Valenciana (ETCV) en funcionamiento, la nueva Ley 5/2014, de julio, de Ordenación del Territorio, Urbanismo y Paisaje de la Comunitat Valenciana (LOTUP) y los Planes de Acción Territorial (PAT) que se derivan de dicha ley, la situación parece diferente. El municipio de Oliva se ve afectado por tres PAT: el Plan de Acción Territorial Forestal de la Comunitat Valenciana (PATFOR), el Plan de Acción Territorial sobre Prevención del Riesgo de Inundación (PATRICOVA), y el de más reciente aprobación Plan de Acción Territorial de la Infraestructura Verde del Litoral (PATIVEL), al cual se han opuesto la mayoría de los grupos políticos municipales. Si a la permisibilidad del ayuntamiento a la hora de construir viviendas fuera de suelos urbanizables y la sobredimensión de su suelo urbanizado, le sumamos la oposición incondicional al PATIVEL a pesar de disponer de mucho suelo urbanizado vacante, entendemos perfectamente las políticas adoptadas por los ayuntamientos en las últimas décadas: “dejar hacer” en la efervescencia del tsunami frente a "no saber qué hacer” en las épocas de crisis (Górgolas, 2017).

Sería interesante estudiar cuáles serán las consecuencias de la aprobación de estas nuevas figuras legales y su grado de efectividad vista la elevada ocupación urbanística de Oliva.

\section{CONCLUSIÓN}

Como conclusión cabe destacar, en primer lugar, la importancia histórica que ha tenido y sigue teniendo la agricultura en el municipio olivense, a pesar de su progresivo abandono y sustitución por usos del suelo de tipo artificial. De acuerdo con los resultados obtenidos, los usos agrícolas ocupaban un $82 \%$ de la superficie del municipio en el año 1956. Actualmente este valor ronda el $50 \%$ y está dedicado exclusivamente al cultivo de la naranja. Aunque los cítricos siguen ocupando la mitad de la superficie municipal, durante las últimas décadas se ha producido un abandono de la actividad agrícola debido a su sustitución por usos artificiales y también a una serie de características estructurales, económicas y socio-culturales del propio sector.

El crecimiento urbanístico de las últimas décadas en Oliva, al igual que en el resto de municipios costeros y grandes ciudades españolas, se ha producido a lo largo de tres booms inmobiliarios (1957-1973; 1986-1991; 1997-2007) interrumpidos entre sí por tres periodos de crisis económica. En el caso particular de Oliva, han tenido especial relevancia el segundo y tercer boom inmobiliarios. Este crecimiento urbanístico se ha producido mayoritariamente en la franja litoral y ha supuesto un profundo cambio en el modelo territorial del municipio en pro de un modelo policéntrico, de baja densidad, segundas residencias y, sobre todo, de carácter altamente insostenible. La ausencia de estrategia territorial, la visión municipalista

2 Decreto 1/2011, de 13 de enero, del Consell, por el que se aprueba la Estrategia Territorial de la Comunitat Valenciana. 
de la ordenación del territorio y la falta de planificación de las últimas décadas y las políticas de crecimiento a cualquier precio se manifiestan, a nivel local, en una serie de problemas ambientales y económicos, como son: el alto consumo de suelo y recursos naturales, el gran impacto ambiental y paisajístico, la incompatibilidad de usos y exposición al riesgo de inundación, los problemas de movilidad interna y externa, el incremento del gasto público y la incapacidad de la administración local para la ordenación espacial de su territorio.

El crecimiento desmesurado de las superficies urbanas en el litoral valenciano se ha producido generalmente como consecuencia de la óptica de planificación municipalista, que a su vez deriva de la falta de unas directrices de desarrollo claras para todo el territorio valenciano. Oliva es un caso claro de este tipo de políticas que han limitado de forma irreversible la capacidad del municipio para adaptarse a escenarios futuros y modelos territoriales más creativos, sostenibles y actuales.

Aunque la situación actual demanda escalas superiores de planificación a las que se han abordado hasta la fecha y se dispone de una Estrategia Territorial para todo el territorio valenciano (y sus Planes de Acción Territorial), se desconoce el grado de efectividad que pueden tener dichos instrumentos de planificación debido al alto grado de ocupación urbana al que ha llegado el municipio. Por este motivo sería interesante estudiar el grado de efectividad que pueden alcanzar los PAT que afectan al municipio y analizar si realmente tienen capacidad para cumplir los objetivos para los que han sido creados, así como las limitaciones y problemas a los que se enfrentan.

Este enfoque metodológico se puede extrapolar a otros municipios del litoral valenciano e incluso del litoral mediterráneo. Puede resultar especialmente interesante la creación de una clasificación de los usos del suelo válida para un territorio más amplio y que permita repetir este estudio en otros municipios litorales, con el objetivo de estudiar las dinámicas territoriales de distintos municipios y analizar las diferencias y semejanzas entre los mismos.

\section{BIBLIOGRAFÍA}

AJUNTAMENT D’OLIVA. (2006): Agenda Local 21 Oliva: Memoria de diagnosis ambiental. Diputació de València. Oliva, pp. 12-16.

ARRIGHI, G. (1994): The long twentieth century. Money, power and the origins of our times. London/New York, Verso.

BAULIES, X. y SZEJWACH, G. (1998): LUCC. Data Requeriments Workshop: survey and needs, gaps and priorities on data for land-use/land cover change research. En Martínez Vega, J., Echavarria Daspet, P., González Cascón, V. "Detección de cambios en los usos del suelo de La Alcarria Conquense: Análisis de su sostenibilidad”. Serie Geográfica 2017-2018, nº 14, pp. 147-161.

BRUEGMANN, R. (2005): Sprawl. A compact history. The University of Chicago, Chicago.

BURRIEL, E. (2008): «La década prodigiosa del urbanismo español (1997-2006) », Scripta Nova, vol. XII, num 270 (64).

BURRIEL, E. (2009): «Los límites del planeamiento urbanístico municipal. El ejemplo valenciano», Documents d'Anàlisi Geogràfica, nº 54, pp. 33-54

EEA (2002): Proceedings of the Technical Workshop on Indicators of Soil Sealing. Technical report, 80. Copenhagen, European Environmental Agency, 62 pp. 
EEA (2006): Urban sprawl in Europe. The ignored challenge. European Environment Agency, Copenhagen.

EWING, R. (1997): «Is Los Angeles-style sprawl desirable?», Journal of the American Planning Association, vol. 63, n ${ }^{\circ}$ 1, pp. 107-126.

EWING, R., PENDALL, R. y CHEN, D. (2002): Measuring Sprawl and its Impacts. Smart Growth America, Washington, DC.

EZQUIAGA, J.M. (2013): «Del planeamiento urbanístico a la ordenación del territorio». Servicio de Publicaciones del Gobierno Vasco, Vitoria, 381 p.

FULTON, W., PENDALL, R. NGUYEN, M. y HARRISON, A. (2001): Who sprawls most? How growth patterns differ across the U.S. Center on Urban \& Metropolitan Policy, July 2001. The Bookings Institution, Survey Series.

GAJA, F. (2005): Política de vivienda, suelo y urbanismo en la España del siglo XX. Bogotá: Universidad de los Andes.

GAJA, F. (2008): «El tsunami urbanizador de la costa mediterránea». Scripta Nova, vol. XII, núm. 270 (66).

GAJA, F. (2012): Antes, durante y después del tsunami inmobiliario en el País Valenciano. En Gaja, F. "Deconstruction. La desconfiguración del litoral mediterráneo español", Editorial Universitat Politecnica de València, València.

GALSTER, G., HANSON, R., RATCLIFFE, M.R., WOLMAN, H., COLEMAN, S. y FREIHAGE, J. (2001): «Wrestling sprawl to the ground: defining and measuring an elusive concept», Housing Policy Debate, vol. 12, n 4, pp. 681-980.

GARCIA-DELGADO, J.L. (1995): La economía española durante el franquismo. Temas para el debate.

GÓRGOLAS, P. (2017): «Burbujas inmobiliarias y planeamiento urbano en España. Una amistad peligrosa», Cuaderno de Investigación Urbanística, $\mathrm{n}^{\circ} 111$.

HARVEY, D. (1985): The urbanization of capital. Studies in the history and theory of capitalism urbanization, John Hopkins University Press, Baltimore.

HARVEY, D. (2000): Spaces of capital. Towards a critical Geography, Routledge, Oxford.

HARVEY, D. (2005): A brief history of neoliberalism, Oxford University Press, Oxford.

HERMOSILLA PLA, J., (2005): Los riegos de La Safor y La Valldigna. Agua, territorio y tradición. Conselleria de Cultura y Educación, Generalitat Valenciana. Valencia, 239 pp.

LLURDÉS-CORR, J.C., TORRES-BAGUR, M. (2015): «Menorca: del tercer boom turistic a la crisi económica i el paper del Pla Territorial Insular», Treballs de la Societat Catalana de Geografia, n ${ }^{\circ} 79$, pp. 39-67.

LOPEZ, R. y HYNES, P. (2003): «Sprawl in the 1990s. Measurement, distribution, and trends», Urban Affairs Review, vol. 38, n 3, pp. 325-355.

MARCOS, P., DEL RIO, S., SAN ROMÁN, M., GONZÁLEZ, M. y RABAL, V. (2013): Destrucción a toda costa. Análisis del litoral a escala municipal. Greenpeace, Madrid, 60 pp.

MEMBRADO-TENA, J.C. (2013): «Sunny Spain: migrantes del sol y urbanismo expansivo en el litoral mediterráneo español», Ciudad y Territorio. Estudios Territoriales, vol. XLV, $\mathrm{n}^{\circ} 178,687-708$.

MEMBRADO-TENA, J.C. (2015): «Migración residencial y urbanismo expansivo en el Mediterráneo español», Cuadernos de Turismo, 35, 259-286. 
MEMBRADO-TENA, J.C. (2017): «La relación entre toponimia urbana y topografía en la Ciutat Vella de València: análisis mediante métodos cuantitativos y cualitativos», Boletín de la Asociación de Geógrafos Españoles, n ${ }^{\circ}$ 44, pp. 361-386.

MUÑOZ CRIADO, A. y DOMENECH GREGORI, V. (2010): Estrategia Territorial de la Comunitat Valenciana: Áreas funcionales. Conselleria de infraestructuras, territorio y medio ambiente. Generalitat Valenciana. Valencia, $436 \mathrm{pp}$.

PASCUAL, J.A., AÑO, C., VALERA, A., POYATOS, M. y SÁNCHEZ, J. (2002): Urban growth (1956-1998) and soil degradation in the municipality of Valencia (Spain). En Faz, A., Ortiz, R. y Mermut, A.R. (Eds.), Sustainable Use and Management of Soils in Arids and Semiarids Regions, Murcia, pp. 396-397.

PONS, A., RULLÁN, O. (2014): «Artificialization and Islandness on the Spanish Tourist Coast», Miscellanea Geographica. Regional Studies on Development, vol. 18, $\mathrm{n}^{\circ}$ 1, pp. 5-16.

PRIETO, F. y RUIZ JOSÉ, B. (2013): Costas inteligentes. Estudio realizado para Greenpeace España. Greenpeace, Madrid, 319 pp.

ROMERO, J. (2010): «Construcción residencial y gobierno del territorio en España. De la burbuja inmobiliaria a la recesión», Cuadernos Geográficos de la Universidad de Granada, no 47, pp. 17-46.

RULLÁN, O. (2011): «Urbanismo expansivo en el Estado Español: de la utopía a la realidad». En Geografía: retos ambientales y territoriales: conferencias, ponencias relatorías, mesas redondas del XXII Congreso de Geógrafos Españoles, Universidad de Alicante y Asociación de Geógrafos Españoles, pp. 165-201.

RULLAN, O. (2011): «La regulación del crecimiento urbanístico en el litoral mediterráneo español», Ciudad y Territorio. Estudios Territoriales, n $^{\circ}$ 168, pp. 279-297.

RUSCA-MESTRE, M.L. y BLÁSQUEZ-SALOM, M. (2017): «De colònia d'estiueig a resort turísticoresidencial. Gentrificació turística de petits nuclis costaners al litoral d'Artà», Treballs de la Societat Catalana de Geografia, no 83, pp. 107-133.

RODRIGUEZ LÓPEZ, J. (2006): «Los booms inmobiliarios en España. Un análisis de los tres periodos», Papeles de Economía Española, n 109, pp. 76-90.

SALOM, J. (2010): «Procesos territoriales y transformaciones recientes del sistema urbano valenciano», Scripta Nova, vol. XV, n ${ }^{\circ} 356$

VALERA, A., AÑO, C. y SÁNCHEZ, J. (2007): «Crecimiento urbano (1956-1998) en el entorno metropolitano de Alacant-Elx (Comunidad Valenciana)», Boletín de la Asociación de Geógrafos Españoles, no 44-2017, pp. 169-186.

VIÑALS BLASCO, M.J. (1996): El marjal de Oliva-Pego (Valencia): geomorfología y evolución de un humedal costero mediterráneo. Conselleria de Agricultura y Medio Ambiente. Valencia, pp. 250-276, 286-289.

YRIGOY, I. (2013): «La urbanización turística com a materialització espacial de l'acumulació de capital hoteler: els casos de Platja de Palma (Mallorca) i Saïdia (Marroc)», Treballs de la Societat Catalana de Geografia, no 75, pp. 109-131.

ZORNOZA, C. (2013): Crecimiento urbanístico en la zona costera de la Comunitat Valenciana (1987-2005). Análisis y perspectivas de futuro. Publicacions Universitat de València. Valencia, $152 \mathrm{pp}$. 